\title{
Borges: literato y filósofo de las paradojas
}

Javier Orlando Aguirre Román

Universidad Industrial de Santander, Colombia

Henry Sebastián Rangel Quiñonez

Universidad Santo Tomás, Colombia 


\section{Borges: literato y filósofo de las paradojas*}

Resumen: el presente texto es una revisión crítica de parte de la obra del escritor argentino Jorge Luis Borges con el fin de evidenciar el talante filosófico de este autor. Para ello se presta especial atención al uso de la noción de infinito y las paradojas que de él resultan. Nuestra conclusión es que, si se va a considerar a Borges como filósofo, se debe concluir que, ante todo, es un "filósofo de las paradojas". Sobre esta base se puede entender su idealismo escéptico.

Palabras clave: Borges, paradojas, infinito, idealismo, filosofía.

\section{Borges: literato and philosopher of the paradoxes}

Abstract: the present text is a critical review of part of the work of the argentine writer Jorge Luis Borges in order to evidence the philosophical attitude of this author. For this, special attention is given to the use of the notion of infinity and the paradoxes that result from him. Our conclusion is that if Borges is considered as a philosopher, one must conclude that he is, above all, a "philosopher of paradoxes" On this basis we can understand Borges' skeptical idealism.

Keywords: Borges, Paradoxes, infinity, idealism, philosophy.

Fecha de recepción: 12 de junio de 2018

Fecha de aceptación: 12 de diciembre de 2018

Forma de citar (APA): Aguirre-Román, J. y Rangel-Quiñonez, H. (2019). Borges: literato y filósofo de las paradojas. Revista Filosofía UIS, 18(1), doi: http://dx.doi.org/10.18273/revfil. v18n1-2019004

Forma de citar (Harvard): Aguirre-Román, J. y Rangel-Quiñonez, H. (2019). Borges: literato y filósofo de las paradojas. Revista Filosofía UIS, 18(1), 89-108.

Javier Orlando Aguirre Román: colombiano. Doctor en Filosofía. Profesor titular de la Escuela de Filosofía, Universidad Industrial de Santander.

Correo electrónico: jaguirre@uis.edu.co

ORCID: 0000-0002-3734-227X

Henry Sebastián Rangel Quiñonez: colombiano. Magíster en Ciencias Estadísticas de la Universidad Nacional de Colombia. Profesor de la Universidad Santo Tomás.

Correo electrónico: henry.rangel@ustabuca.edu.co

ORCID: 0000-020002-6745-6753

*Artículo de reflexión derivado de investigación. 


\section{Borges: literato y filósofo de las paradojas}

\section{Introducción}

El infinito es un concepto elusivo y paradójico. Por ejemplo, ¿quién no aceptaría que el todo es siempre mayor que la suma de sus partes? A primera vista parece evidente que el conjunto de todos los números naturales tiene que ser mayor que el conjunto de los todos los números múltiplos de mil. Sin embargo, si hacemos coincidir el número uno con el número mil, el número dos con el número dos mil, el número tres con el número de tres mil, y así indefinidamente, bien podríamos hacer coincidir cada uno de los números naturales con un múltiplo de mil. Por lo tanto, ya que ningún elemento del conjunto de los naturales quedaría sin emparejar con el conjunto de los miles, debemos concluir forzosamente que ambos conjuntos tienen el mismo número de elementos.

Como es conocido, con la metodología consistente en hacer coincidir elementos de un conjunto en lugar de contar uno por uno, el alemán matemático George Cantor fue capaz de descubrir las características sorprendentes del infinito. Entre ellas, podemos recordar su más famoso teorema según el cual hay tantos puntos en el segmento de una línea infinitesimal como los hay en todo el universo. Los lectores de Borges seguramente encontrarán resonancias inmediatas con la famosa historia de El Aleph.

Borges, de hecho, al igual que muchos filósofos y matemáticos estuvo muy interesado por el infinito, y su interés fue constantemente manifiesto en toda su obra. En este sentido, una forma de explorar las dimensiones filosóficas de Borges puede ser la de mostrar cómo el concepto de infinito y sus implicaciones en la teoría de las paradojas son desarrollados de forma sistemática a lo largo de su obra literaria. Y por sistemática acá entendemos: diseñadas con un fin específico.

La hipótesis aquí propuesta es que las historias de Borges en las que se presenta el infinito tienen un objetivo particular que va más allá de "lo meramente literario". Para esto mostraremos la funcionalidad de la noción de infinito en los siguientes textos de Borges: "Una Nueva refutación del tiempo", "La perpetua carrera de Aquiles y la tortuga", "Avatares de la tortuga", "La Biblioteca de Babel" 
y "El jardín de senderos que se bifurcan". Estos cinco textos nos ayudarán a construir una interpretación de (parte de) la obra literaria de Borges como una teoría filosófica que utiliza las paradojas relacionadas con el infinito con el fin de ilustrar su idealismo (y sus límites).

La obra literaria de Borges expone constantemente varios tipos de paradojas relacionadas con la noción de lo infinito. Del mismo modo, en sus numerosos ensayos, algunos de ellos dedicados a la materia de las paradojas, parece que Borges aceptara un tipo idealista de filosofía. Según la hipótesis aquí planteada esos dos aspectos de la obra de Borges están profundamente conectados en la medida en que el infinito y las paradojas que de él se derivan constituyen una prueba de la verdad del idealismo.

La hipótesis enunciada se desarrollará en cinco pasos. En primer lugar, se realiza un breve recorrido por el estado de la relación de Borges y la filosofía; para ello nos apoyamos, en gran parte, en la tesis doctoral de Andrés Lema-Hincapié titulada Borges..., ifilósofo? Creación Literaria y filosofía en la obra de Jorge Luis Borges; documento que junto con otros escritos centrarán al lector en los principales discursos que se han desarrollado sobre este tema. En segundo lugar, se presentan los principales argumentos de Borges contenidos en "Una Nueva refutación del tiempo"; estos argumentos nos permitirán mostrar el compromiso de Borges con una filosofía idealista. En tercer lugar, exponemos dos cuentos de Borges en el que se desarrolla la idea de lo infinito. Estas historias son "La Biblioteca de Babel" y "El jardín de senderos que se bifurcan". Posteriormente, con base en "La perpetua carrera de Aquiles y la tortuga" y "Avatares de la tortuga", se muestra la relación entre el idealismo de Borges y su uso de la noción del infinito en las historias, para finalmente proporcionar algunas conclusiones acerca el idealismo de Borges y su extensión paradójica.

\section{Algunas consideraciones sobre Borges y la filosofía}

La relación entre Borges y la filosofía ha sido un tema de constante investigación de los comentaristas de la obra de Borges, pues no hay un consenso entre si considerar los escritos de Borges como textos filosóficos o como literarios ${ }^{1}$; esta discrepancia persiste pese a las afirmaciones del mismo Borges al sugerir que sus escritos no deben ser vistos con la agudeza filosófica sino con ligereza literaria, algo que se devela en algunas partes de su obra y en entrevistas, tal como la citada por Lema-Hincapié:

\footnotetext{
1 Sobre el tema García (2001) explica que se puede hacer una distinción entre un trabajo filosófico y un texto literario ya que el primero se enfoca más en el contenido, en el mensaje a trasmitir, contrario al segundo que se enfoca en la forma de lo que se trasmite. Es por ello que los textos literarios presentan problemas en la traducción, pues su esencia es intrínseca al idioma, problema que debe carecer los trabajos filosóficos.
} 


\begin{abstract}
Yo me he pasado parte de mi vida leyendo a algunos filósofos: Berkeley, Hume, Schopenhauer; luego, un escritor alemán que nadie parece haber leído, Fritz Mauthner, autor de Crítica del lenguaje y de un diccionario de filosofía. He leído muchas historias de la filosofía. Pero nada más, yo no soy un filósofo. Lo que hice, mejor dicho, lo que he tratado de hacer, es aprovechar las posibilidades literarias de la filosofía, o de los sistemas filosóficos. [...] No es que yo piense personalmente que eso corresponde a la verdad, quiere decir que he visto las posibilidades poéticas de los sistemas filosóficos. Nada más (Lema-Hincapié, 2008, pp. 2-3).
\end{abstract}

En estas palabras, consignadas en la revista La Palabra y el Hombre de 1976, Borges deja claro que la filosofía, en su obra, solo le sirve como elemento poético². Aun así, no todos los críticos parecen creer esto y la relación de Borges y la filosofía no culmina con estas palabras.

Si queremos demostrar la relación entre filosofía y Borges podríamos empezar por enunciar los filósofos leídos por Borges y su influencia ${ }^{3}$. Como se anotó anteriormente, Borges afirma haber leído a cuatro autores especialmente: Berkeley, Hume, Schopenhauer y Mauhner. Pero, son los dos últimos donde recae su mayor sustrato; a Schopenhauer se le atribuye vínculos temáticos con sus obras El mundo como voluntad y representación (1985) y Parerga y Paralipómena (2000). El tema recurrente de la obra de Borges de un mundo como ilusión, el tiempo configurado circularmente, la distinción entre el sueño y la vigilia o el pesimismo existencial son algunos temas que, como lo enuncia Lema-Hincapié (2008, pp. 63-64), fueron adquiridos a partir de los textos de este filósofo. Por otro lado, a Mauhner se le atribuye el monismo en Borges, entendido como el "evitar toda pregunta por un mundo más allá de las representaciones" (Lema-Hincapié, 2008, p. 72), así como los "conceptos de significado contextual, catálogo de mundos y superstición de la palabra" (73).

De similar manera, pero con menor consenso, se ha acrecentado la polémica sobre la relación de Borges con la filosofía, vista como la influencia directa sobre filósofos como Foucault ${ }^{4}$ y/o su papel como escritor de trabajos filosóficos. Sobre este último aspecto Lema-Hincapié (2008) hace un detallado recorrido a través de los comentaristas que se han acercado a este tema. Apoyados en Lema-Hincapié

\footnotetext{
${ }^{2}$ Hay otras referencias sobre esta auto definición de Borges como literato, aquí presentamos una más del texto Imágenes, memorias, diálogos: "No soy ni filósofo ni metafísico —Aclara Borges— lo que he hecho explotar, o explorar — es una palabra más noble — las posibilidades literarias de la filosofía. Creo que eso es licito" (Martínez, 2012, p. 83).

${ }^{3}$ Puede consultarse la revista Variaciones Borges donde yacen un nutrido conjunto de artículos que exploran, entre otras cosas, la exégesis de la obra de Borges en relación a los filósofos que este autor ha citado a través de su obra. Véase: https://www.borges.pitt.edu/journal consultado el 5 de junio del 2017.

${ }^{4}$ Foucault en su libro Las palabras y las cosas advierte en sus primeras líneas que está inspirado en el texto de ficción "El idioma analítico de John Wilkin" de Borges. En Rabinovich (2006) se puede encontrar una reflexión sobre el papel de este texto en la obra de Foucault.
} 
se pueden proponer cuatro tipo de posturas generales: 1) los que afirman, pese a lo dicho por Borges, que las ficciones borgeanas son filosofía, clasificando sus textos en diferentes corrientes filosóficas que van desde la metafísica, el idealismo, el constructivismo, la filosofía del lenguaje, hasta el escepticismo. Entre este grupo se encuentran Nuño (2012), Rest (1976), Wahl (1964), Sierra Mejía (1982), Champeau (1990), Serna Arango (1990), Kaminsky (1994), E. Gutiérrez (1994), Mateos (1998) y Olaso (1999). 2) Los indecisos e imprecisos, que no son determinantes al definir los escritos borgeanos como filósofo o como un mero literato. Entre estos encontramos a Barrenechea (2000), G. Gutiérrez (1998), Sucre (1967), Alazraki (1974), Ferrer (1971) y Echavarría (1983). 3) Los que definitivamente piensan que Borges solo usó la filosofía como argumento literario para embellecer sus escritos. Entre los que resaltan Sábato (1964), Massuh (1980) y Sturrock (1977). Y 4) los que no dudan en definir a Borges no solo como filósofo sino como el forjador de la pos-modernidad, vinculando la obra borgeana con pensamientos de la filosofía del siglo XX como la fenomenología de Heidegger, el estructuralismo, el posestructuralismo, la filosofía analítica y posanalítica. En este grupo encontramos los comentarios de Blüher y De Toro (1992) y De Toro (1992, 1999a, 1999b).

En este punto la discusión queda abierta, pero, para efectos del presente trabajo es menester ocupar un lugar en ella, por esto las siguientes líneas encajan en el primer grupo de críticos que encuentran en los textos de Borges más que mera prosa, proporcionando un fecundo campo que crea y plantea temas filosóficos.

\section{El idealismo de Borges en su "Nueva refutación del tiempo"}

El ensayo de Borges "Nueva refutación del tiempo" es un texto cuyo carácter paradójico se nota desde el principio. En el tercer párrafo del prólogo, Borges nos advierte acerca de la contradicción entre el título y el contenido de su ensayo. En palabras de Borges, "porque decir es nueva (o antigua) una refutación del tiempo es atribuirle un predicado de índole temporal, que instaura la noción que el sujeto quiere destruir" (Borges, 1974, p. 757). Además, justo después del título, en el primer párrafo del prólogo, Borges argumenta que si la refutación se hubiese publicado en otro tiempo, es decir, hacia la mitad del siglo XVIII, su valor habría sido diferente. Por lo tanto, aun si la refutación fuera exitosa, es decir, si es una buena refutación, cosa que en el primer párrafo se acepta, para Borges el concepto que está siendo refutado de alguna manera afecta y determina la naturaleza y el valor de la refutación.

La refutación se divide en dos partes. Cada una escrita en un tiempo diferente (1944 y 1946); algo que pone de relieve una vez más la naturaleza paradójica de la refutación. En ambas partes Borges acepta las consecuencias del idealismo de Hume y quizás también de Berkeley, las cuales recaen en la esencia de los objetos 
y el "yo", y, a su vez, pretende extenderla a la naturaleza del tiempo. Según Borges, una vez que se admite el argumento idealista, es inevitable ir más allá. "Lo repito: no hay detrás de las caras un yo secreto, que gobierna los actos y que recibe impresiones; somos únicamente la serie de esos actos imaginarios y de esas impresiones errantes. ¿La serie? Negados el espíritu y la materia, que son continuidades, negado también el espacio, no sé qué derecho tenemos a esa continuidad que es el tiempo" (Borges, 1974, p. 761). En la segunda parte de la refutación, Borges afirma, "Fuera de cada percepción (real o conjetural) no existe la materia; fuera de cada estado mental no existe el espíritu; tampoco el tiempo existirá fuera de cada instante presente" (768).

En este sentido, la refutación de Borges se basa en la afirmación de la autonomía absoluta de cada momento de nuestra experiencia. Existe cada momento que vivimos, señala Borges, pero no su combinación imaginaria. En ambos ensayos Borges está interesado en mostrar las consecuencias de su tesis, lo que implica, en términos generales, la negación de la coexistencia, así como de la sucesión.

En el ensayo, Borges nos ofrece el ejemplo del amante engañado que se engaña a sí mismo al imaginar que mientras él estaba feliz pensando en la fidelidad de su amada, ella lo estaba engañando. El engaño mayor consiste en creer en la realidad material de la coexistencia. Lo cierto es que cada estado experimentado es absoluto; por lo tanto, su felicidad no podría haber sido contemporánea con la traición (Borges, 1974, p. 762). Es por esto que la esperanza y el miedo pierden el sentido en la medida en que "siempre se refieren a eventos futuros; es decir, a hechos que no nos ocurrirán a nosotros, que somos el minucioso presente" (762). La sucesión, por lo tanto, es también una ilusión.

Hay que notar que la refutación de Borges no implica que el tiempo no existe en absoluto. La refutación consiste en señalar que el tiempo sólo existe como algo ajeno o externo a los acontecimientos del mundo. En el segundo ensayo, Borges ilustra su argumento con el sueño de Chuang Tzu. Después del relato, Borges se pregunta:

¿Cómo, abolidos el espacio y el yo, vincularemos esos instantes a los del despertar y a la época feudal de la historia china? Ello no quiere decir que nunca sabremos, siquiera de manera aproximativa, la fecha de aquel sueño; quiere decir que la fijación cronológica de un suceso, de cualquier suceso del orbe, es ajena a él, y exterior (1974, p. 769).

La radical consecuencia que Borges quiere sugerir en su refutación, una vez que se niega la coexistencia y la sucesión, se refiere a la posibilidad de las repeticiones. En efecto, Borges dice: 
En China, el sueño de Chuang Tzu es proverbial; imaginemos que de sus casi infinitos lectores, uno sueña que es una mariposa y luego sueña que es Chuang Tzu. Imaginemos que, por un azar no imposible, este sueño repite puntualmente el que soñó el maestro. Postulada esa igualdad, cabe preguntar: esos instantes que coinciden ino son el mismo? ¿No basta un solo término repetido para desbaratar y confundir la historia del mundo, para denunciar que no hay historia? (Borges, 1974, p. 769).

Todas las posibilidades que se derivan de esta concepción idealista del tiempo parecen ser muy desconcertantes, y Borges es totalmente consciente de ello. Pero también es consciente de los muchos absurdos que resultan de una concepción diferente $y$, de alguna manera, quiere hacernos comprender estas contradicciones en su obra literaria.

\section{El trabajo literario de Borges: dos historias paradójicas sobre el infinito}

Si aceptamos una noción de tiempo objetiva e independiente de nuestra mente, el literato-filósofo Borges está preparado para enfrentarnos con todos los interrogantes derivados y relacionados con el infinito puesto que la idea de un tiempo infinito es una consecuencia inevitable de afirmar la existencia de un único tiempo en el que todas las cosas están vinculadas como en una cadena; el tiempo independiente de nosotros es una cadena hecha de enlaces infinitos. En este sentido, no es una sorpresa que, en sus numerosas obras, Borges presenta el infinito estrechamente relacionado con la idea de realizar una cadena (infinita) ininterrumpida de acciones.

Borges afirma en "La perpetua carrera de Aquiles y la tortuga" que el infinito es una de las muchas imaginaciones horribles que la mente humana ha inventado. Para Borges, el infinito es "[...] Palabra (y después concepto) de zozobra que hemos engendrado con temeridad y una vez consentida en un pensamiento, estalla y lo mata" (Borges, 1974, p. 248). En este contexto podemos encontrar un punto de conexión entre dos elementos de la obra de Borges: por un lado, su idealismo, ya que está expuesta en su refutación del tiempo, y, por otro, su interés por las paradojas y el infinito.

En la revisión de Borges del libro de Edward Kasner y James Newmann, Las matemáticas y La imaginación, él presenta tres paradojas: la paradoja del mentiroso, Cervantes hombre ahorcado, y la paradoja de los conjuntos de todos 
los conjuntos que no se incluyen así mismos ${ }^{5}$. Después, Borges agrega esta otra, tal vez inventada por él: un joven desea convertirse en un hechicero en Sumatra. Todo depende de la respuesta de una pregunta simple sobre el futuro. El candidato tiene que responder a esta pregunta correctamente. El asistente examinador le pregunta al joven si va a fallar o aprobar el examen. El joven candidato responde que fallará ¿Qué debe hacer el examinador? Si el joven no aprueba el examen, significa que él predijo el futuro y, por lo tanto, él debe pasar. Pero si pasa el examen, significa que él no predijo el futuro y, por lo tanto, él fallará. Vale la pena resaltar que esta paradoja crea una situación en la que lo más racional y lógico es quedarse para siempre realizando un movimiento incesante, es decir, preguntando si el joven candidato debe fallar o aprobar el examen. Borges no explica los detalles de esta paradoja, pero la concluye al afirmar: "Ya se presiente la infinita continuación" (Borges, 1974, p. 277).

El contexto de la paradoja de Borges es una situación práctica en la que debe tomarse una decisión, es decir, el candidato debe aprobar o reprobar el examen. Sin embargo, la respuesta del candidato transforma esta situación en una en la que los examinadores se quedarían para siempre preguntándose si el candidato debe pasar o no. En este sentido, la paradoja de Borges crea una situación en la que una serie de acciones debe ser realizada sin cesar; algo que requeriría, entre otras cosas, un tiempo infinito.

Del mismo modo, en muchos cuentos de Borges el infinito parece estar relacionado con la idea de realizar una cadena ininterrumpida de acciones. El

\footnotetext{
Recordemos estas tres paradojas: 1) La paradoja del mentiroso narra la historia del Cretense Epiménides cuando afirmó: Todos los cretenses son unos mentiroso, dejando la pregunta de si el mismo Epiménides decía no la verdad o no. 2) la paradoja de Cervantes hombre ahorcado se encuentra en la obra Don quijote de la Mancha en el capítulo LII de la segunda parte, allí se habla de un puente que para ser cruzado debían jurar frente a cuatro jueces su destino y quehacer luego de cruzar, los jueces decidían si lo que se decía era verdad o mentira, el castigo para la mentira era la horca y el premio de la verdad era cruzar el puente. Así pues, la paradoja se crea cuando un hombre al pretender pasar el puente jura que su destino y quehacer es morir ahorcado en la horca que allí se encuentra, lo que genera la pregunta ¿Se debe dejar pasar a esta persona o debe ser ahorcada? 3) La paradoja de los conjuntos que se autocontienen se remonta a la teoría de conjuntos de Cantor pero fue Bertrand Russell quien la popularizó y redefinió en lo que se conoce como la paradoja del Barbero, dicha antinomia cuenta la historia de un Barbero que debe afeitar a todas las personas que no se afeitan a sí mismas, dejando la pregunta ¿̇e debe afeitar el barbero a sí mismo o no? (consúltese Rengifo, 2004). El lector podrá reflexionar que cada posible respuesta a las preguntas generan una refutación que invalida la respuesta, por ejemplo: si afirmamos que Epiménides decía la verdad, tendríamos que aceptar que Todos los cretenses son unos mentirosos y por ende que el mismo Epiménides ha dicho una mentira y no una verdad. Si en el caso de Cervantes afirmamos que el hombre debe ser ahorcado, aceptaríamos que el hombre dijo la verdad y por ende lo que por ley le pertenece es cruzar el puente y no morir en la horca. O si pensamos en que el barbero debería afeitarse a sí mismo, tendríamos que refutar que el barbero solo afeita a las personas que no se afeitan a sí mismas y por ende él mismo no debería hacerlo. Ver, entre otros, Beall (2007), Cantini (2004), Field (2008), Garciadiego (1992), Kritchman y Raz (2011), McGee (1991), Yuting (1953), Simmons (1993). Uno de los libros más usados en las universidades para el estudio de este tema es el de Sainsbury (2009), titulado Paradoxes.
} 
infinito, así entendido, es una fuente activa de paradojas; siguiendo este punto de vista, vamos a presentar dos cuentos de Borges, "La biblioteca de Babel" y "El jardín de senderos que se bifurcan" ${ }^{6}$.

\section{a: El Infinito en "La Biblioteca de Babel"}

El tema de "La Biblioteca de Babel" no es una creación de Borges. En su ensayo "La Biblioteca Total", Borges explica que el tema fue realmente creado por Gustav Theodor Fechner y expuesto por primera vez en La Biblioteca universal escrita por Kurd Lasswitz en 1901. Según Borges, en esa historia Lasswitz afirma que un alfabeto universal reducido al menor número posible de signos, necesitaría sólo veinticinco símbolos, es decir, veinte dos letras, la coma, el punto y el espacio. Las diferentes combinaciones de estos símbolos ortográficos serían suficientes para expresar todos los pensamientos expresables en cualquiera de los lenguajes existentes actuales. El conjunto de tales combinaciones comprendería la Biblioteca total. Según Borges, todo estaría contenido en esa biblioteca, todo lo pensable, cada libro coherente que pudiese ser escrito, pero también cualquier permutación posible de cada uno de esos libros, lo que significa que en la Biblioteca total la mayoría de los libros no tendría sentido y sería ininteligible.

Borges no afirma categóricamente que la Biblioteca es infinita. Pero sí quiere explorar cómo la Biblioteca puede estar relacionado con ese concepto. Al principio, dice, "El universo (que otros llaman la Biblioteca) se compone de un número indefinido, y tal vez infinito, de galerías hexagonales" (Borges, 1974, p. 465). Más tarde, sin dejar de describir a la Biblioteca, Borges dice:

En el zaguán hay un espejo, que fielmente duplica las apariencias. Los hombres suelen inferir de ese espejo que la Biblioteca no es infinita (si lo fuera realmente ¿a qué esa duplicación ilusoria?); yo prefiero soñar que las superficies bruñidas figuran y prometen el infinito... (465).

El narrador de la historia indica dos axiomas que gobiernan la naturaleza de la Biblioteca; primero, la Biblioteca existe ab aeterno, y en segundo lugar, los símbolos ortográficos son veinticinco. Por lo tanto, al menos temporalmente, la Biblioteca es de hecho infinita. El narrador también nos habla de un bibliotecario genio que ha hecho dos descubrimientos cruciales. En primer lugar, todos los

\footnotetext{
${ }^{6}$ Existe una postura contraria a la que vamos a presentar y es la propuesta de De Toro (1999b) quien afirma que no existen paradojas en Borges sino rizomas: "El crítico [De Toro] reduce todos estos procedimientos [regressus in infinitum, la infinita postergación, la paradoja infinita, la empresa imposible] a uno solo, que los incluye a todos: el regressus in infinitum [...]. De Toro habla de rizoma, en cuanto "estructura nómada". En la medida en que la paradoja solo acontece si hay endoxa [mundo mimético referencial realista] [...] Borges para De Toro crea mundos ajenos de todo mimetismo, en esta literatura no hay paradoja", pese a lo anterior no podemos negar la posibilidad de la existencia de la paradoja, vista como una especia de experimento mental el cual pretende poner a prueba el concepto de tiempo en un contexto idealista (Lema-Hicampie, 2008, p. 61).
} 
libros, no importa lo diversos que sean, se componen de los mismos elementos: el espacio, el punto, la coma, y las veintidós letras del alfabeto. En segundo lugar, en la gran Biblioteca no hay dos libros idénticos:

De esas premisas incontrovertibles dedujo que la Biblioteca es total y que sus anaqueles registran todas las posibles combinaciones de los veintitantos símbolos ortográficos (número, aunque vastísimo, no infinito) o sea todo lo que es dable expresar: en todos los idiomas (Borges, 1974, p. 467).

No obstante, el número de libros no puede ser infinito, en el sentido estricto. Borges nos dice que hay cinco estantes contra cada una de las paredes del hexágono. Cada estante tiene 35 libros. Cada libro tiene 410 páginas, y cada página tiene 40 líneas. Por último, cada línea tiene 80 letras. Por lo tanto, sabemos que hay 16.400 líneas en cada libro y 1.312 .000 letras en cada libro. Por último, ya que sólo 25 símbolos se pueden utilizar y, puesto que sabemos que ningún libro puede ser repetido, pero sí se pueden repetir los elementos dentro de una misma línea, entonces, tendríamos, por los principios de la permutación que, los posibles libros o historias resultantes serian ; un número absolutamente enorme, aunque no infinito, pero sí incalculable ${ }^{7}$. Dicho cálculo es cierto siempre y cuando se pueda interpretar las 80 letras de cada línea como 80 espacios que pueden ser ocupados por las 22 letras y los dos signos de puntuación más el espacio. De lo contrario, si Borges sólo considera 80 letras, sin incluir los signos de puntuación y el espacio, sería imposible calcular la cantidad de espacio en cada línea y simultáneamente resultaría imposible expresar un aproximado de las diferentes permutaciones de historias factibles a ser creadas, pues, como el mismo Borges asegura, hay: "[...] obras que no difieren sino por una letra o una coma" (Borges, 1974, p. 469).

Sin embargo, si la Biblioteca es finita, hay algo que no encaja bien. De hecho, al principio de la historia, el narrador dice que, como todos los hombres en la Biblioteca, él ha estado buscando un libro, es decir, el catálogo de catálogos. Luego, casi al final, el narrador nos recuerda una vez más sobre este libro: "En algún anaquel de algún hexágono (razonaron los hombres) debe existir un libro que sea la cifra y el compendio perfecto de todos los demás: algún bibliotecario lo ha recorrido y es análogo a un dios" (Borges, 1974, p. 469).

Es posible vincular esta alusión de un libro que es un compendio perfecto de todos los demás o de un catálogo de todos los catálogos con la idea de la existencia de un conjunto de todos los conjuntos o lo que se asemeja con la idea

${ }^{7}$ La finitud de la Biblioteca es reconocida por Quine (2005): "It is interesting, still, that the collection is finite. The entire and ultimate truth about everything is printed in full in that library, after all, insofar as it can be put in words at all. The limited size of each volume is no restriction, for there is always another volume that takes up the tale -any tale, true or false- where any other volume leaves off. In seeking the truth we have no way of knowing which volume to pick up nor which to follow it with, but it is all right there". 
de infinito. Supongamos que el conjunto es el catálogo de los catálogos, y , y son todos los catálogos existentes en la Biblioteca. Entonces, tenemos $C=\{C 1, C 2$, C3\}. Pero es evidente que hemos encontrado un catálogo que no está catalogado: C. Por lo tanto, podríamos pensar que deberíamos encontrar un catálogo $\mathrm{C}^{\prime}$ que lo incluye de esta manera $C^{\prime}=\{C, C 1, C 2, C 3\}$. Pero ahora el catálogo $C^{\prime}$ no está catalogado, y tal vez deberíamos buscar un catálogo $C^{\prime \prime}$, que lo incluyera y así sucesivamente, de manera indefinida e infinitamente. Por lo tanto, iexiste realmente este libro? Parece que sí, puesto que la Biblioteca es total y tiene un número finito de libros. Pero si realmente estamos buscando este libro total, también parece que siempre seremos capaces de pensar en la existencia de un libro nuevo y diferente que lo contenga. Al final, el narrador propone una solución a esta contradicción:

La biblioteca es ilimitada y periódica. Si un eterno viajero la atravesara en cualquier dirección, comprobaría al cabo de los siglos que los mismos volúmenes se repiten en el mismo desorden (que, repetido, sería un orden: el Orden). Mi soledad se alegra con esa elegante esperanza (Borges, 1974, p. 471).

Esta solución implica la posibilidad de un catálogo de los libros, con propiedades del infinito similares a la de Dios. Recordemos que la biblioteca es infinita pero no en espacio, ya que se sabe que las permutaciones posibles de su definición son finitas (o sea contiene un número limitado de libros, aunque incontable como se mencionó) lo que hace infinita a la "Biblioteca de Babel" es la continua relación entre sus libros, las historias que entre libros se complementan y se contienen entre sí. Otra similitud con el infinito se encuentra en el periódico desorden de los libros, el desorden periódico hace pensar en un arquitecto, en un infinito que define la materia finita, casi inconmensurable de la biblioteca. Este argumento es intrigante pues genera, a partir de una estructura finita de materia compuesta por líneas, páginas, caracteres, libros y anaqueles, la existencia de algo infinito y ordenado dentro del caos.

Al final, lo infinito es la relación entre libros que existen en el decálogo de decálogos, claro está que se mantiene la pregunta de si realmente es posible que éste exista. Cuestión que para Borges no es problemática: "Lo repito: basta con que un libro sea posible para que exista. Sólo está excluido lo imposible. Por ejemplo: ningún libro es también una escalera [...]" (Borges, 1974, p. 469). Con ello pretende afirmar que cualquier historia es posible ser contada en esa biblioteca. Pero, podríamos pensar en un pequeño cambio arbitrario en sus características para analizar si realmente es posible aceptar la "totalidad" de la biblioteca. Pensar, por ejemplo: en 800, 200 o, aún mejor, en 1 página en vez de 410, produce libros. Es claro que las historias varían en su extensión, dejando en duda la posibilidad de expresar todo lo expresable en el finito número de libros. 
En todo caso, la solución explícita del narrador implica que la infinitud de la biblioteca no es un número irracional, sino la de un decimal periódico, como $6,15 \widehat{48}$. Esta solución, para bien o para mal, hace posible que los seres humanos realicen una acción incesante, es decir, buscar el catálogo de todos los catálogos siempre. De lo anterior podemos afirmar que pese a su finitud en espacio se puede pensar en una infinita relación entre los hombre y la Biblioteca total pues ésta última no tiene comienzo ni fin; tiene un número finito de libros es verdad, pero la vasta cantidad de ellos confunden al espectador y lo hace pensar en una infinita extensión de anaqueles y pasillos. Más aún, los residentes de estas bibliotecas, conscientes de ser mortales, podrían imaginar que el tiempo en la biblioteca es infinito por la cíclica ordenación de los libros, las historias entrecruzadas y la perpetua simetría en los espacios. Para ellos no hay un ahora ni un después. Esta idea, esto es, la idea de un tiempo cíclico infinito, aparece de forma explícita en El jardín de senderos que se bifurcan.

\section{b: El Infinito en "El jardín de los senderos que se bifurcan"}

"El jardín de los senderos que se bifurcan" también introduce la idea de un libro infinito. En esta historia leemos a Ts'ui Pên, el gobernador de su provincia natal. Él es un jugador de ajedrez, un poeta, y también un calígrafo que aprendió astronomía, astrología y la interpretación infatigable de los libros canónicos. Sin embargo, abandona todo esto para escribir un libro y hacer un laberinto, pero, cuando muere no se encuentra nada excepto sus manuscritos caóticos.

Todo el mundo pensaba que Ts'ui Pên participaba de dos actividades diferentes, porque en algunos momentos decía "Estoy escribiendo un libro" y en otros "Estoy construyendo un laberinto". Pero la verdad es que su libro y su laberinto son una y la misma cosa. Este secreto se descubre en una carta póstuma escrita por Ts'ui Pên en la que escribe: "Dejo a los varios porvenires (no a todos) mi jardín de senderos que se bifurcan" (Borges, 1974, p. 477). El descubridor del laberinto es un famoso sinólogo llamado Stephen Albert. Al principio él no entiende cómo es posible que un libro sea infinito, pero cuando lee la carta de Ts'ui Pên, finalmente resuelve el enigma:

[...] El jardín de senderos que se bifurcan era la novela caótica; la frase varios porvenires [(no a todos) (sic)] me sugirió la imagen de la bifurcación en el tiempo, no en el espacio. La relectura general de la obra confirmó la teoría. En todas las ficciones, cada vez que un hombre se enfrenta con diversas alternativas, opta por una y elimina las otras; en la del casi inextricable Ts'ui Pên, opta -simultáneamente- por todas ellas. Crea, así, diversos porvenires, diversos tiempos, que también proliferan y se bifurcan [...] En la obra de Ts'ui Pên, todos los desenlaces posibles ocurren; cada uno es el punto de partida de otras bifurcaciones (Borges, 1974, pp. 477-478). 
Quien descubrió el laberinto es consciente de que el mayor problema que había intrigado a Ts'ui Pên es el problema de la naturaleza del tiempo. No obstante, en la gran obra de Ts'ui Pên no hay una sola mención de ese problema; la palabra "tiempo" no se utiliza ni una sola vez. Pero el descubridor tiene una explicación para esto. Para Albert, está claro que en una adivinanza cuyo tema es el ajedrez, la única palabra prohibida es, precisamente, "ajedrez". En este sentido, El jardín de senderos que se bifurcan aparece como una enorme adivinanza cuyo tema es el tiempo, lo que implica que esa palabra no puede ser mencionada.

En el diálogo final de la historia entre Albert y Yá Tsun, la persona con quien Albert comparte su descubrimiento, este último afirma:

\begin{abstract}
La explicación es obvia: El jardín de senderos que se bifurcan es una imagen incompleta, pero no falsa, del universo tal como lo concebía Ts'ui Pên. A diferencia de Newton y de Schopenhauer, su antepasado no creía en un tiempo uniforme, absoluto. Creía en infinitas series de tiempos, en una red creciente y vertiginosa de tiempos divergentes, convergentes y paralelos. Esa trama de tiempos que se aproximan, se bifurcan, se cortan o que secularmente se ignoran, abarca todas las posibilidades (Borges, 1974, p. 479).
\end{abstract}

Al final de la historia, el descubridor del infinito sufre un terrible destino. Albert es asesinado por Yá Tsun, quien resultó ser un espía de Alemania durante la Primera Guerra Mundial e, irónicamente, un pariente de Ts'ui Pên. La captura de Yá Tsun por los británicos era inminente. Pero antes de que esto ocurriera, él deseaba transmitir la ubicación de un nuevo parque de artillería británico a sus patrones alemanes. Ese parque de artillería se encontraba en una ciudad llamada Albert. Esta es la razón por la cual Yá Tsun decide matar al Dr. Albert Steven, ya que la noticia del asesinato seguramente aparecería en los periódicos británicos y, por lo tanto, los alemanes sabrían que tendrían que bombardear a la ciudad llamada Albert.

Volveremos al tema de la muerte de Albert en las conclusiones que pasamos a proponer en el acápite siguiente de nuestro texto.

\title{
5. A manera de conclusión: Borges, filósofo de las paradojas
}

En "La perpetua carrera de Aquiles y la tortuga", Borges expone la paradoja de Zenón, que él llama "una joya", presenta algunas refutaciones, y da su propia opinión sobre el tema. Esta opinión, impertinente y trivial según el propio Borges, es que

[...] Zenón es incontestable, salvo que confesemos la idealidad del espacio y el tiempo. Aceptemos el idealismo, aceptemos el crecimiento concreto de 
lo percibido, y eludiremos la pululación de abismo de la paradoja. ¿Tocar a nuestro concepto del universo, por ese pedacito de tiniebla griega?, interrogará mi lector (Borges, 1974, p. 248).

El tema de la paradoja de Zenón aparece de forma explícita en "Nuevos avatares de la tortuga". En este texto, Borges afirma que hay un concepto que corrompe y trastorna el resto de los conceptos, y este terrible concepto no puede ser el concepto del mal, porque el mal está limitado a la ética. Para Borges, el concepto absolutamente corruptor es el infinito. Al final de este ensayo, Borges parece admitir su propio objetivo intelectual: "Admitamos lo que todo idealista admite: el carácter alucinatorio del mundo. Hagamos lo que ningún idealista ha hecho: busquemos irrealidades que confirmen ese carácter" (Borges, 1974, p. 258). Borges también nos recuerda acerca de Novalis, quien una vez escribió que el mago más grande de todos los tiempos sería aquel capaz de echar sobre sí mismo un hechizo tan perfecto y completo que lo llevaría a creerse sus propias fantasmagorías como fenómenos reales y autónomos. Borges dice que nosotros, como seres humanos, somos los mejores magos:

Nosotros (la indivisa divinidad que opera en nosotros) hemos soñado el mundo. Lo hemos soñado resistente, misterioso, visible, ubicuo en el espacio y firme en el tiempo; pero hemos consentido en su arquitectura tenues y eternos intersticios de sinrazón para saber que es falso (Borges, 1974 , p. 258).

En este sentido, Borges estaría de acuerdo con Barwise y Etchemendy quienes afirman que "La importancia de una paradoja nunca es la paradoja en sí, sino que es un síntoma de. Una paradoja demuestra que nuestra comprensión de algún concepto básico o un conjunto de conceptos crucial está viciado, que los conceptos se descomponen en casos límite" (Barwise y Etchemendy, 1987, p. 4).

Por lo tanto, si se va a considerar a Borges como filósofo, se debe concluir que, ante todo, es un "filósofo de las paradojas"8. Sobre esta base se puede entender su idealismo escéptico que le permite utilizar el infinito en su rol de literato para recordarnos de la existencia de esas "grietas tenues y eternas de la sinrazón", que nosotros mismos hemos creado en nuestro sueño del mundo. Las nociones objetivas de espacio y tiempo son ilusiones creadas por nosotros. Sin embargo, en

\footnotetext{
${ }^{8}$ Aunque a veces suele olvidarse, lo cierto es que la "filosofía de las paradojas" es un campo filosófico con una historia muy larga. Como podemos leer en la enciclopedia filosófica de Stanford, "Paradoxes form a natural object of philosophical investigation ever since the origins of rational thought; they have been invented as part of complex arguments and as tools for refuting philosophical theses (think of the celebrated paradoxes credited to Zeno of Elea, concerning motion, the continuum, the opposition between unity and plurality, or of the arguments entangling the notions of truth and vagueness, credited to the Megarian School, and Eubulides of Miletus). Paradoxes—termed as Insolubilia-form also a substantial part of logical and philosophical investigations during the Middle Ages". Sobre el tema se puede consultar especialmente a Sainsbury (1995) y a Sorensen (2003).
} 
esas ilusiones hemos creado un concepto que las destruye o, al menos, que nos recuerda su carácter ilusorio. Este es el concepto de lo infinito. En este sentido, la obra literaria de Borges busca construir y mostrarnos las irrealidades que confirmarían el idealismo, como Borges mismo parece reconocerlo en "Avatares de la tortuga".

Y, sin embargo, en última instancia, no es posible deshacerse de las paradojas. Es por esto que concluimos que, antes que un idealista o un escéptico, Borges es un filósofo de las paradojas. La refutación del tiempo de Borges es de hecho muy singular. Tras el prólogo, las primeras líneas de esta refutación nos advierten que el autor no cree realmente en ella. Según Borges,

En el decurso de una vida consagrada a las letras y (alguna vez) a la perplejidad metafísica, he divisado o presentido una refutación del tiempo, de la que yo mismo descreo, pero que suele visitarme en las noches y en el fatigado crepúsculo, con ilusoria fuerza de axioma (Borges, 1974, p. 759).

Del mismo modo, al final de su "visitante nocturno", en el párrafo final, Borges utiliza un adverbio de tiempo ("And yet, and yet...") que recuerda que el tiempo sigue ahí, a pesar de la refutación. Por esta razón, "Negar la sucesión temporal, negar el yo, negar el universo astronómico, son desesperaciones aparentes y consuelos secretos" (Borges, 1974, p. 771). Independientemente de la validez o solidez de nuestros argumentos para refutar el tiempo, al final, es decir, cuando se acaba el tiempo, el río nos va a borrar a nosotros; el tigre que somos nos destruirá; el fuego que somos nos consumirá. En palabras de Borges "El mundo, desgraciadamente, es real; yo, desgraciadamente, soy Borges" (Borges, 1976, p. 771).

Por lo tanto, la muerte parece ser el antagonista final de la gran refutación de Borges. En "La Biblioteca total" el narrador nos dice que miles de hombres han muerto en busca del catálogo de catálogos. Del mismo modo, Stephen Albert muere dramáticamente en "El jardín de senderos que se bifurcan". Y Borges ies el fantástico trabajo de Borges lo suficientemente potente como para derrotar al tigre, el río, y el fuego? A pesar del entusiasmo con el que leemos a Borges, la sana lógica parecen obligarnos a responder negativamente. Borges ya no existe y lo más probable es que en algún momento no existirá ningún lector de Borges. Solo nos queda intentar consolarnos con las genialidades humanas, creadoras de paradojas e infinitos, y con la genialidad de algunos humanos, como Borges, capaces de revelarnos de forma estéticamente hermosa la majestuosidad y (a la vez) los débiles cimientos de esas creaciones. 


\section{Referencias}

Alazraki, J. (1974). La prosa narrativa de Jorge Luis Borges: Temas/Estilo. Madrid: Gredos.

Barise, J. y Etchemendy, J. (1987). El mentiroso: un ensayo de la verdad y la circularidad, New York: Oxford.

Barrenechea, A. (2000) La expresión de la irrealidad en la obra de Jorge Luis Borges y otros ensayos. Buenos Aires: Del Cifrado.

Beall, J. (2007). Revenge of the Liar. New Essays on the Paradox. New York: Oxford University Press.

Borges, J. L. (1974). Obras completas 1923-1972. Buenos Aires: Emecé.

Blüher, K. (1992). Postmodernidad e intertextualidad en la obra de Jorge Luis Borges. En K. Blüher y A. de Toro (Coords.), Jorge Luis Borges: Variaciones interpretativas sobre sus procedimientos literarios y bases epistemológicas (pp. 129-143). Frankfurt am Main: Vervuert.

Cantini, A. (2004). On a Russellian Paradox about Propositions and Truth. En G. Link (Ed.), One Hundred Years of Russell's Paradox (pp. 259-284). Berlin and New York: Walter de Gruyter.

Champeau, S. (1990). Borges et la métaphysique. Paris: J. Vrin.

De Olaso, E. (1999). Jugar en serio: Aventuras de Borges. Ciudad de MéxicoBuenos Aires: Universidad Nacional Autónoma de México, Paidós.

De Toro, A. (1992). El productor 'rizomático' y el lector como 'detective literario': la aventura de los signos o la postmodernidad del discurso borgesiano (intertextualidad-palimpsesto deconstrucción-rizoma). En K. Blüher y A. de Toro (Coords.), Jorge Luis Borges: Variaciones interpretativas sobre sus procedimientos literarios y bases epistemológicas (pp. 145-83). Frankfurt am Main: Vervuert.

De Toro, A. (1999a). Borges/Derrida/Foucault: pharmakeus/heterotopia o más allá de la literatura ('hors-littérature'): Escrituras, fantasmas, simulacros, máscaras, carnaval, y... Atlön/Tlön, Ykva/Uqbar, Hlaer, Jangr, Hrön(n)/Hrönir, Ur y otras cifras. En K. Blüher y A. de Toro (Coords.), Jorge Luis Borges: Variaciones interpretativas sobre sus procedimientos literarios y bases epistemológicas (pp. 138-163). Frankfurt am Main: Vervuert. 
De Toro, A. (1999b). ¿Paradoja o rizoma? 'Transversalidad' y 'escriptibilidad' en el discurso borgeano En A. de Toro (Ed.), El siglo de Borges: Retrospectiva/Presente/ Futuro, Tomo 1 (pp. 173-208). Madrid-Frankfurt am Main: Iberoamericana; Vervuert.

Echavarría, A. (1983). Lengua y literatura de Borges. Barcelona: Ariel.

Ferrer, M. (1971). Borges y la nada. London: Támesis.

Field, H. (2008). Saving Truth from Paradox. New York: Oxford University Press.

Garciadiego, A. (1992). Bertrand Russell and the Origins of Set-theoretic "Paradoxes". Basel: Birkhäuser.

Gracia, J. (2001). Borges's "Pierre Menard": Philosophy or Literature? The Journal of aesthetics and art criticism, 59(1), 45-57.

Gutiérrez, E. (1994). Borges y la doctrina de la reversibilidad temporal. En G. Kaminsky (Comp.), Borges y la filosofía (pp. 39-50). Buenos Aires: Instituto de Filosofía; Facultad de Filosofía y Letras, Universidad de Buenos Aires.

Gutiérrez, R. (1998). Ensayo de interpretación. En J. C. González (Ed.), Jorge Luis Borges: El gusto de ser modesto (pp. 1-81). Bogotá: Panamericana.

Kaminsky, G. (1994). Borges y la filosofía. Instituto de Filosofía y letras: Universidad de Buenos Aires.

Kritchman, S. y Raz, R. (2011). The surprise examination paradox and the second incompleteness theorem. Notices of the American Mathematical Society, 57, 1454-1458.

Lema-Hincape, A. (2008). Borges... ¿ifilósofo? Creación literaria y filosofía en la obra de Jorge Luis Borges (Tesis de Doctorado en Filosofía). Faculty of the Graduate School of Cornell University, Ithaca, Estados Unidos de América.

Martínez, J. (2012). Nuño, Borges y la filosofía. Episteme, 32(1-2), 81-96.

Mateos, Z. (1998). La filosofía en la obra de Jorge Luis Borges. Buenos Aires: Biblos.

Massuh, G. (1980). Borges: Una estética del silencio. Buenos Aires: Belgrano.

McGee, V. (1991). Truth, Vagueness, and Paradox: An Essay on the Logic of Truth. Indianapolis and Cambridge: Hackett Publishing. 
Nuño, J. (1986). La filosofía de Borges. Ciudad de México: Fondo de Cultura Económica.

Paradoxes and Contemporary Logic. Recuperado el 9 de julio de 2017 de https:// plato.stanford.edu/entries/paradoxes-contemporary-logic/\#ParEarDev189

Rabinovish, S. (2006). La Risa de un filósofo. Metapolítica, 47, 71-76.

Rest, J. (1976). Borges y el pensamiento nominalista. Buenos Aires: Librerías Fausto.

Sábato, E. (1964). Les deux Borges: L'argentin, la métaphysique et le tango. En J. L. Borges et al., Cahiers de L'Herne (pp. 168-178). Paris: L'Herne.

Sainsbury, R. (2009). Paradoxes. Cambridge: Cambridge University Press.

Schopenhauer, A. (1985). El mundo como voluntad y representación, (Vol. 2). Barcelona: Orbis.

Schopenhauer, A. (2000). Parerga and Paralipomena: Short philosophical essays, (Vol. 1). Oxford: Oxford University Press.

Serna, J. (1990). Borges y la filosofía. Pereira: Gráficas Olímpica.

Sierra, M. (1982). Esbozo de una semántica borgeana. Cuadernos de filosofía y letras, 5(1-2), 51-62.

Simmons, K. (1993). Universality and the Liar: An Essay on Truth and the Diagonal Argument. Cambridge: Cambridge University Press. DOI: 10.1017/ CBO9780511551499

Sorensen, R. (2005). A brief history of the paradox. New York: Oxford University Press.

Sturrock, J. (1977). Paper Tigers: The Ideal Fictions of Jorge Luis Borges. Oxford: Clarendon Press.

Sucre, G. (1967). Borges, el poeta. Ciudad de México: Universidad Nacional Autónoma de México.

Rengifo, M. (2004). Categorias una interpretación de la filosofía análitica. Bogotá: Universidad Externado de Colombia. 
Revista virtual, Variaciones Borges. Recuperado de ttps://www.borges.pitt.edu/ journal

Yuting, S. (1953). Paradox of the class of all grounded classes. Journal of Symbolic Logic, 18(2), doi:10.2307/2268942

Wahl, J. (1964). Les personnes et l'impersonnel. En J. L. Borges et al., Cahiers de L'Herne. Paris: L'Herne.

Quine, W. (July 18, 2015). Universal Library. Recuperado de http://jubal.westnet. com/hyperdiscordia/universal_library.html 